\title{
DISCUSSING DISCUSSIONS: ONLINE INSTRUCTOR BEST PRACTICES
}

\author{
Teresa L. Avery \\ University of Waterloo-Renison / University of Toronto - OISE (CANADA)
}

\begin{abstract}
A structured literature review was conducted to examine the range of theoretically framed studies examining online learning discussions within higher education. Key words to guide the retrieval were: "online learning" AND engagement or participation AND "higher education" or college or university not "MOOC" or MOOCs" AND teacher or instructor or professor. This preliminary study did not differentiate between course discipline but did focus on higher learning, specifically university or college level courses that were not technical, certificate, graduate or professional. The study used four consecutive years of peer-reviewed ERIC documents. Of the 132 documents retrieved in the initial broad search, only 55 fit the search parameters, and only four of these were literature review-based. The remaining studies were primarily empirical, often focusing on one factor of online teaching or learning.
\end{abstract}

The scarcity of current information is significant. Also interesting was the underlying emphasis on the Community of Inquiry (COI) framework, based on Garrison's seminal work in 2000 which highlighted the importance of engagement and community in knowledge acquisition. COI or constructivism is directly referenced in 19 of the 55 works and 31 of the 55 works employed key terms of COI theory.

From a review of these papers, it appears that instructor decisions about how to structure a course, what to include, and how and when to become involved are ad hoc: the end result is that instructors' involvement in courses is variable and not guided by clear pedagogical principles. While the COI framework provides a good working model and a wide range of part of partial solutions and suggestions, there still remains a need for a more definitive guide.

This study organizes relevant findings in the area of technical and learner considerations, as well as within the teaching, social and cognitive presence of the instructor, taken from the COI framework. Information, presented in a cohesive, comprehensive document within a valid pedagogical framework can better inform busy educators who desire to transform their own teaching based on relevant research.

Future study could expand and critique this model, more fully integrating other models and looking at course-related variables more closely. Qualitative, quantitative and longitudinal studies can be designed which not only develop and expand the methodology suggested as currently viable within a learning community, but which also build on the potential for online learning to go beyond reproducing traditional courses online.

Keywords: Best practice, collaboration, Community of Inquiry, forum, instructor facilitation, instructor modelling, meaningful engagement, online discussion.

\section{INTRODUCTION \& METHOD: FRAMING THE REVIEW}

This research began with a desire to better inform instructors in online learning within higher education about best practices. The scarcity of current information is significant. The following search parameters were used:

("online learning" AND (engagement OR participation) AND ("higher education" OR college or university) NOT ("MOOC" OR "MOOCs") AND (teacher OR instructor OR professor)) AND peer (yes)

The search used ERIC, including a 3 year span beginning January 2012. This search retrieved 138 peer reviewed articles, with 55 subsequently deemed relevant. Only 4 were literature-review based or included significant summary material. Very little of the information available at this time is currently presented in a cohesive, comprehensive document within a valid pedagogical framework which can better inform busy educators who desire to transform their own teaching based on relevant research; 
nor, is there sufficient research to thoroughly ground the pedagogical use of many of the evolving potential best practices.

\subsection{An emphasis on Community of Inquiry}

A key finding was the underlying emphasis on the COI framework, based on Garrison's seminal work in 2000 which highlighted the importance of engagement and community in knowledge acquisition. Of the 55 works retrieved, 15 reference Garrison and 13 of these reference a COI model; 12 works, 6 of which do not directly reference $\mathrm{COI}$, reference Constructivism. This means that 19 works of 55 , or over $1 / 3$ of the works, clearly referenced and employed Garrison's COI theory to inform their research about online course discussion. Even works which did not directly referenced $\mathrm{COI}$ often could be understood as framed within the $\mathrm{CO}$ and constructivist ideology, mainly through the author's use of common $\mathrm{COI}$ terms such as social presence, teaching presence and a community of learners. While this criteria is more subjective, the researcher found at least 31 of the 55 works used key terms of $\mathrm{COI}$ theory; only 6 works referenced the ideas of $\mathrm{COI}$ within a context that could be seen as inquiring or debating aspects of the relevance of this popular model.

A COI model "outlines the behaviours and processes required to enable knowledge construction in asynchronous online environments through the development of various forms of 'presence'.... teaching-,social-, and cognitive presence" [1]. The Social Constructivist model also places higher learning within a community of learners where interaction informs, and incites acquisition of knowledge at varying levels. Metacognition is linked to online learning within the COI framework, best developed online within a social context. The essential skills of metacognition are "a set of higher knowledge and skills to monitor and regulate manifest cognitive processes of self and others" [2]. Higher order knowledge acquisition, especially in an online environment, includes key aspects of COI: selfregulation, ownership of learning, generative learning and knowledge construction [3]. A COI framework informs instructors on how students construct meaning, mediating between "reflection, action, degree of critical thinking and inquiry" [2].

\subsection{Other ideas can lead to a better understanding}

Even when additional frameworks for understanding or improving one or more aspect of online instructor best practices are used, these are most often mentioned as informing a COl theory. For example, problem based learning is a way to "fully embrace online learning environment" and empower learners within a "natural state of learning" in a real world setting in a digital context [4], [5]. The online community is described within the Scholarship of Teaching and Learning (SOTL) as an 'ecological site' which can create diverse online learning spaces for "education in the margins"; allowing the "somewhat disparate and often isolate off-campus student" to feel more a part of the whole [6]. A more committed engagement framework speaks to online courses which can enhance the learning experience within a learning community [7]. The appreciative inquiry method in the literature retrieved dealt more specifically with adult learners, or an appreciative androgyny; yet, there is some value in looking more closely at external versus internal motivation and the organizational setting of the learning experience [8]. The situational theory of publics, and the idea that an "individual's ability to recognize the value of a situation and the desire and ability to remove obstacles in that situation will lead to greater involvement in that situation" can inform instructors about how students may decide to face in-course challenges and overcome constraints to participation [9]. Finally, the psychological contract is discussed more fully within this research as it applies most readily to specific instructor based methods and understanding [10].

\subsection{A definitive guide?}

Online education evolves rapidly. Perhaps more important than a list of best practices is an understanding of a framework that can guide good practices, and a willingness to identify optimal practices that work, understanding why they work, and how, or if, they can apply to different course constructs or cohorts of students. The larger study from which this paper is derived organizes key findings within the area of technical and learner considerations, and the teaching, social and cognitive presence of the instructor using a $\mathrm{CO}$ framework for organizing information: suggested best practices, presented in a cohesive, comprehensive document within a valid pedagogical framework, may better inform busy educators who desire to transform their own teaching based on relevant research. 


\section{RESULTS AND DISCUSSION: THE IDEAL ONLINE INSTRUCTOR WITHIN A COGNITIVE INQUIRY FRAMEWORK}

\subsection{The teaching presence of the online instructor}

Teaching presence is thought of as the element within $\mathrm{COI}$ that sustains sharing subject matter expertise in a variety of direct and indirect forms [11] and including "online instructional skills such as organization, design, discourse facilitation, and direct instruction" [12].

\subsubsection{Online Reflective Task Framework}

Teaching presence sets the framework for the online course. An online reflective task framework can assist teachers in evaluating student participation and can enable teachers to provide appropriate prompts. Teachers can be made aware not only that students have varying levels of interactivity, but that different students benefit more from prompting. Within the psychological contract perspective, teaching presence also begins to establish a "community of practice" with "systematic interventions" which can more efficiently allow novices to gain full membership [10]. From a psychological contract perspective, the "teaching presence plays the most critical role in how students evaluate learning" [10]. Students want instructors robustly involved in their online learning.

Establishing foundational guidelines allows learners to know exactly what is expected of them, particularly in an online course when the chain of communication may be more cumbersome. Sometimes a course is created by an instructor and largely facilitated by a teaching assistant. Specific guidelines and protocols can help prevent a disconnect between student and instructor. Always, "expectations should be made explicit" [13]. Clear and specific guidelines about participation, marking schemes, choices, flexibility of assignments, etc. should be accessible at the start of the course, easy to find within the navigation tools, and can be part of an orientation session [14], [15]. One successful course, based on COI principles, used 'priming' activities at the start of the course [16].

\subsubsection{Delivering Scaffolded Materials}

The teaching presence is readily seen in teacher-scaffolded material delivery within a traditional classroom, instructors can modify lectures or delivery of course material based on more easily observed gaps in knowledge. Online course material is more rigidly set before the class begins, so teachers need to be acutely aware that the same gradual delivery of some material may be necessary. Many courses require one concept to be understood before the next concept is taught. Online courses can allow students to navigate through courses in a non-linear fashion. Teachers who require some concepts to be learned before others can use technology to require a completed quiz, or discussion posting, or other measurement of understanding, before subsequent material is unlocked or available. This aspect of scaffolding is identified as a key factor in a technology-based online course [17]. Teacher directed scaffolding, within the delivery of course can allow students to progressively assimilate ideas; and an understanding of the available options for instructors will augment their teaching presence online [18]. One potential advantage to online courses is the fact that scaffolding can be tailored more individually to a student or group of students; the next lecture or lesson does not have to be delivered at the same time to an entire class.

\subsubsection{Integrating Learning Objects and Learning Strategies}

Teaching presence can effectively demonstrate links between teaching material and learning objectives. Sometimes the instructors, when looking at their own teaching presence, also need to have time to adjust to a more learner centric and active learning style of course delivery [17]. Over time and through engagement, students and staff become more satisfied with their perception of the importance of the Online Learning Environment (OLE) [19]. By actively teaching students the aspects of technology which are directly related to compelling learner-focused activities, the instructor becomes more familiar with how these learning objects can become part of the context and contribute to course objectives. Students appreciate those learning objects the instructor "places value on online and integrates" [15]. Additional explanations or teaching objects are considered more valuable if the goals of the course are embedded in active learning and assessment.

Teaching presence is linked to building specific course-related skills, learner strategies and technological skills. Often students' skills are ad hoc, since most students are never really taught how to navigate an online course. Time management and accessing materials within the course is often overwhelming. Learner strategies are often "centered around scanning or skimming other students' 
contributions" [19]. The online learning environment and learner characteristics affect learning strategies. Teachers need to facilitate "moderating strategies" within the course structure and also in a leadership role, offering guidance, assisting in selection and sorting of materials, and helping students manage time [20]. Administrative and/or technical guidance is important early in a course, which can "assist the student to become accustomed to the fully online mode of learning early on" [21]. Students who are in first year have a crucial need of teacher facilitation and participation in areas of pedagogical and technical support so that their quality of learning is not compromised [22].

\subsection{The social presence of the online instructor}

Fully online courses still must satisfy the need for a 'social presence' for an online instructor. Online learning detractors and even supporters often undergird praise of online learning with a lament about the isolation of students exacerbated by an instructor who never meets them face-to-face. Some institutions have blended courses in unique mixes of hybrids which offer introductory or exam preparation classes, real-time office hours, or alternated weeks in class and online. Research does not determine the extent needed, or the best way to manifest, the online social presence of the instructor. Social presence can be instrumental and can "potentially lead to more effective learning" [23]. There remains still, a challenge for institutions, educators and students for whom a hybrid of online and traditional is not feasible or, for multiple reasons, desirable

\subsubsection{Presence Versus Being Present}

In spite of the emphasis of the COI Framework on 'social presence', this presence is not necessarily optimally manifest as instructors or students may imagine by the term social. Studies into use of social media as platforms for learning, and online communities for academic and peer engagement are important. Yet, social presence of an educator is not contingent on an externally located teaching presence or a manifest social personality. The educator who is present socially within the online learning environment as a composite of his teaching presence and cognitive presence is much more in demand.

Learners, especially those who past online introductory courses, will choose online learning for a variety of reasons, and a camaraderie with their instructor is not a key consideration. Learners who choose online learning often do so because of the mode of learning is convenient, flexible, autonomous and readily accessible [25]. Elements of satisfaction for Western students in online courses are more closely related to the content, guidelines, organization, and flexibility of the courses. The instructor's role in providing feedback in a timely fashion is important, but students do not indicate a strong desire to see or hear instructors [25]. When students are asked to determine "critical success factors" they support previous findings. Of the top ten reasons for dropping course, only one was related to the instructor and addressed teaching style, and even then an absence of teaching presence was not a consideration [25].

Oztok and Brett conducted a meta-analysis concerning students' collaborative work in an online environment [25]. Significant in their study, in addition to student-related factors of peer collaboration, is the consideration of literature which demonstrates that students "enter the online world because it is suitable for independent learners" [25]. In fact, the review found that students who choose to take online courses often do not have a strong desire to have a personal connection. Preisman, who reports about graduate students, indicates that for these learners, who could be considered more inherently autonomous, there was indeed 'minimal evidence' that re-creating a greater sense of teaching presence was even an effective use of teacher time or effort [25]. Preisman stressed the focus needs to be on quality best practice online strategies that positively impact student learning, and the "need for an instructor to be present as opposed to having a presence" [25].

\subsubsection{Communicating and contributing}

One component of instructor social presence is the idea of the instructor contributing an online presence to the online "collaborative conversation" which ideally characterizes online learning discussions. The aspect of social presence of the teacher is very closely tied not to an online personality, but to a facilitator who engages students in learning communities often structured through asynchronous discussion [23]. A student asserts: "The purpose of online discussions is to talk! If we didn't discuss, it would be a self-taught class" [23]. While teachers struggle to find a balance for their own interaction, this balance is not achieved by a more well-defined online person, but by creating a better virtual community through modeling and clear guidelines. 
Instructors need to recognize that in spite of the fact that students share frequently and often within the confines of social media, students are often unclear about how to communicate effectively within an academic forum. Student engagement in discussions is not automatic, and intervention by instructors is often "one of the most critical factors" [24]. The instructor, as catalyst and navigator shapes the engagement and defines quality interaction [24]. Early in the course, an instructor can facilitate community by introducing themselves and encouraging students to do likewise [24]. Instructors have been labeled the "sage on the stage" the "guide on the side" or even the "ghost in the wings" [24]. The ideal social presence of an instructor has not been established clearly, and bears further study, but the imperative of the instructor's role in guiding the class towards richer online collaboration is undisputed.

\subsubsection{Actual and Perceived Availability}

Social presence is important as part of the Community of Inquiry framework, yet the priority is not for a friendly affable instructor who meets more emotional or purely social needs. Students do not want a contrived social presence, but a real composite of course instructor with an actual and perceived availability [9]. Integral are the clearly expressed expectations, course guidelines, and timely effective feedback which are the main components facilitated by this effective investment [11]. Part of establishing an online social presence, though, is not in the role of the instructor being seen and heard, but in developing an environment through facilitation which can "support students' communication, coordination and the development of their collaborative skills" [25]. A social presence for an instructor is not facilitated by a long introduction, but by fulfilling interaction, meaningful comments during the course, and the "viewpoints points and opinions of recognizable instructors" [26] who facilitate the class with "multiple avenues of communication [9]. Availability can be from practical inputs such as revolving virtual office hours, or use of instant messaging systems. Social networks can be used, as can video or audio conferencing. As more definitive research begins to inform the area of availability as an aspect of social presence, the instructor must continue to realize that for students choosing online education, these more personable platforms are tools to extend the instructor's role as a teaching presence.

\subsection{The Cognitive Presence of the Instructor}

Of the three components within the COI learning, cognitive presence of the instructor is in many ways the most elusive to define, the least investigated as a separate construct, and arguably the most important. Aspects of learner engagement within the online learning environment are not often delineated as critical to cognitive presence. Yet, many concepts fall within the scope of the instructor facilitating or modelling best practices which encourage critical thinking, metacognition, reflective personal assessment, motivation and collaboration. Cognitive learning is at the heart of what educators desire in all modes of learning: that intangible aha moment when a learner internally assimilates ideas which become part of the lens from which they see the world and take action or make decisions. The cognitive presence is "the extent to which participants in an online discussion can or are willing to engage in critical thinking and use communication as a means to construct meaning" [27]. Cognitive presence is also manifest in the "exploration, construction, resolution, and confirmation of understanding through collaboration and reflection" [27].

\subsubsection{Facilitating Critical Thinking, Designing Assessments, The Psychological Contract}

Critical thinking often involves instructors asking the right questions. Students do not naturally gravitate to higher levels of cognition within traditional or online environment. Part of teaching is to encourage the level of thinking which prompts learners to question what is being taught as it fits into what they know, and as it could affect what they will do. The right questions [13] can intrinsically link the design and facilitation of a good course [28]. Reflective questions can be as important as the presence of the teacher. Questions should be reflective of the material learned and the potential application of the material [13]. Indeed probing questions can be part of an instructor "constructing effective dialogue" within the online environment for critical, reflective thinking [13]. Park emphasizes that critical thinking should not be taken for granted but "needs to be explicitly explained, modelled, taught, and expected" [28]. Espasa, Guasch and Alvarez emphasize the knowledge construction component of online education which is facilitated by a directed communication exchange [18].

While the design of assessments and feedback could be placed in the 'teaching presence' of an instructor, linking this definitive instructional communication to cognitive presence emphasizes the critical learning aspect of effective feedback. Students in one study, although the course was blended, 
had their top complaint as lack of feedback from instructors [29]. Indeed, for students who were highly self-regulated and voluntarily choose online courses, timely, detailed feedback from the instructor was more important to them than social or teaching presence [28]. Graduate students, perhaps differently motivated than undergraduate students so not the focus of this study, still provided interesting selfreported feedback about the instructor and the goals of the course. The only statistically significant factor when evaluating the course which could be linked directly to the instructor was related to the prompt: "The instructor clearly communicates the course objectives and how they relate to the program's goals and mission at the beginning of the course" [11]. This study separated students into two cohorts with the same course material and teacher, but with the course delivered online or face-toface.

The study found formative feedback was one of the best investments a teacher could make to support autonomous work within the course. Feedback from an instructor needs to implement a "different set of teaching skills" and to incorporate "practices and strategies that maximize potential benefits" [27]. Instructor feedback needs to have depth and be related to the critical and meaningful knowledge which is part of higher level thinking. Within a socially constructivist idea of learning, each participant, and especially the instructor, is responsible for enhancing the learning environment and giving facilitative prompts add to the potential for cognitive processing and benefits [27].

Studies of online course environments as part of a psychological contract between learner and instructor emphasize the importance of the instructor giving feedback specific to a student's abilities and accomplishments. Feedback, in this framework, is part of the balanced contract or unwritten agreement between instructor and student. The transactional process of an instructor providing ways for a student to improve and learn becomes the basis for meeting obligations that the student perceives as integral to the fulfilling of this contract [25]. In return, a student strives to fulfill his or her obligations. Adhering to the constructive prompts and participating in the online environment optimally can lead to a more fulfilling online experience for the student, and even for the peer cohort who benefits from the more robust exchange. The psychological contract theory bears more study, but findings about the importance of timely feedback and appropriate intervention are identified in other studies as key to "facilitate active participation and collaboration, problem solving and knowledge production" [28].

\subsubsection{Promoting Metacognition and Autonomy}

Metacognition should also not be taken for granted. Metacognition describes a level of learning concerned with how a student controls or self-monitors his own thinking and learning. Students need to be taught how to be active learners and need to be given strategies to succeed in a forum that often more challenging when it "lacks the aspect of face to face interaction" [29]. One key example which benefits from specific instructor guidelines and modelling is the forum for group projects. Students not only need very definite structure and expectation for online group projects, they also benefit from instructors informing, educating and guiding them about how to be facilitators within their group [2]. Students do develop dimensions of metacognition, "including knowledge, monitoring, and regulation" within these projects. However, using these skills effectively requires direct "instruction, motivation, and guidance....particularly in relationship to the regulation of metacognition and co-construction of meaning" [2]. Group projects which involve online peer evaluation indicate that students do have the potential to stimulate learning with other students, but this process is also best when modelled first by a good instructor.

Peer feedback in general is easier online: the more neutral environment seems to stimulate discussion and encourage facilitate more implementation of the feedback given [18]. Given the time constraints within online courses, for an effective peer network to develop, teacher facilitation including giving concrete practical direction and modelling can assist students to provide more useful feedback to their peers.

Teachers often need a different set of skills in order to facilitate higher levels of learning online and to promote metacognition. Proponents of subject-centered teaching also discuss the importance of teaching students to "learn how to learn" and encouraging students to "allow themselves to be confused" [30]. Optimally, students are taught not only how to benefit from assessment and feedback but, "how to read between the lines of assessment tasks" and to begin to decipher what the goals and rationale may have been behind choosing a particular assignment or method of completing an assignment [30]. Some of this understanding is provided by detailed assignment guidelines which incorporate syllabus elements in an accessible, relatable format. Also, students who are taught to 
look beyond the particular assessment in a particular course gain an autonomy over their own learning which could manifest itself in the potential for a higher level of learning and application of that learning.

An instructor who supports student autonomy also enables self-efficacy, which has a direct correlation to metacognition. Student autonomy puts an active student in a position of self-directing his or her own learning, and self-efficacy involves also directing the strategies used for obtaining that learning and applying it. When students actively participate in learning tasks, this self-determination is a "manifestation of students' motivation" [31]. Teachers who encourage, by reward or direct support, activities which are autonomous can facilitate further "engagement, performance and persistence [31]. Students apparently perceive more personal autonomy when instructors support their interests, preferences, values and psychological needs. The fact that students will also exhibit emotional connections with instructors who support their autonomy can give support to the importance of cognitive presence as it informs even a more social understanding of the instructor. Giving choices increase the perception of internal control and increase self-efficacy [32].

Autonomy can be practically supported by instructors. In allowing autonomy and encouraging student motivation and engagement, the cognitive presence of an instructor must also provide the necessary balance; too much freedom can be overwhelming and even 'wasteful', making students resent the efforts necessary for making decisions about too many course options [31]. Yet, there is a rich environment for choice, rationale and personalization which each support student autonomy. Teacherdetermined choices about topics with predetermined parameters can include a limited number of strategies to explore as well as student-led decisions about group size and presentation format. Additionally, providing rationale for an assignment allows students to concur with or endorse a particular activity, making even limited or no choice acceptable within a realm of autonomy because the student experience is inherently enhanced by seeing future value. Personalization of an assignment within instructor-defined guidelines is another way of making the course material meaningful and allowing students to become invested in what they are learning. Student personalization opportunities often have a reciprocal enriching value to the instructor who can then have more insight into student topics of interest as well as allowing the foundation for "creating a larger learning community" with "personally relevant and meaningful connections" between content and "one's place in the world" [31]. An online interactive format gives the opportunity for instructors to actively engage students to develop habits of autonomy.

\subsubsection{Modelling Reflective Personal Reflection and Networking}

Instructors can also manifest a cognitive presence as they enable students to critically and accurately reflect upon their own learning strategies. When students are actively engaged in course-specific material, they are primed for instructor-led training that increases their awareness of their own aptitude to learn [33]. Students with low self-regulated learning (SRL) have a tendency to over-rate their own learning skills, which often leads to lack of success in courses when students do not feel they needed to access information as often, or do not use course materials to the extent for which they were designed [33]. Teaching students strategies about how to learn, and more specifically how to learn in an online environment, can be an effective use of teacher time and effort.

Part of modelling, and teaching students how to act and interact in an online environment, is encouraging good networking skills. Students were found to often lack the skills necessary to manage their own learning points, including the ability to "find and categorize content for future retrieval and traverse networks of interest" [21]. Instructor facilitation through assessment, feedback and modelling of the skills involved in utilizing all resources in an optimal fashion has implications for future learning as well. Learners who are enabled in networking, including the ability to network with other individuals and peers in a mutually beneficial exchange, will also further their lifelong learning [21]. Part of the collaboration process online is also all participants understanding enough of the process so that students and instructors are comfortable within the online environment and are confident participating [22]. One example of effective modelling is an online reflective blog authored by an instructor, who not only modelled the learning process but provided a window through which students could examine "exemplary technological and pedagogical practice". This is one example of an instructor who facilitated students to "follow quality engagement" [22].

\subsubsection{Supporting Collaboration Towards Higher Learning}

Facilitating autonomous learning within an online environment not only allows instructors to encourage and support further peer interaction and collaboration but also "has the potential to transcend the course and be applicable to future contexts and life situations" [31]. Cognitive presence of the 
instructor, unlike social or teaching presence, is more dependent on learner behaviour and aptitude. The cognitive presence of the teacher, when manifested in the learner in reciprocal cognitive knowledge, also depends on online self-regulatory cognitions and behaviours. There is a unique compensation effect on leaners who either come into the course with more cognitive presence or who begin to develop a more effective cognitive presence as a result of teacher modelling or facilitation. Learners can self-regulate to attain higher levels of cognition, even in the absence of teaching and social presence. In an online learning environment, cognitive learning seldom takes place without selfregulation, ownership of learning, generative learning, and knowledge construction [3]. Cognitive skills can be examined as they manifest themselves within an individual's and group's knowledge construction within an online environment. Kang expands Garrison, Anderson \& Archer's definition of cognitive learning as "the extent to which learners in a community of inquiry are able to construct meaning through sustained reflection and discourse," [3] linking cognitive learning to higher order knowledge acquisition.

In an online course learning is no longer an individual endeavour: students interact with other students, with the content and with the instructor. Student engagement is not automatic though, and there is a lack of clarity about the ideal role of instructors [24]. As this interaction is realized at a deeper level, there is a potential for not just rote memorization, but for "negotiation and internalization of knowledge" and the asynchronous discussion forums are widely used to facilitate this interaction [24]. The quality of the discourse is "far more important" than the quantity of posts or interactions; yet, the discussion must allow "ubiquitous access" [13], [27].

Studies need to go beyond the surface and frequency considerations, and begin to examine "general facilitation characteristics" as instructors play "an active role in initiating and carrying a discussion forward" [24]. Discussion is not the only form of communication, but this element is "receiving increased attention" due to its "impact on both participation and critical thinking" [27]. Discussion is often the way instructors help students "clarify and obtain a correct understanding of the course content," yet on a deeper level instructors are thought of by many to be "critical to the success of an online discussion" [24]. The role of the student is debated: one school of thought maintains students should not have the responsibility to determine direction, and one emphasizes students should become more active and "construct their own knowledge" [24].

Data analysis of one study indicates the fact that "periodic feedback from instructors is always valued highly by students and keeps student on track" calling such an online cognitive presence "essential" [24]. Yet, there is a danger of too much instructor participation which can prompt students to respond more to instructor comments instead of participating in active collaboration with their peers [23]. Additionally, instructors and students "may understand participation and engagement differently" [34]. In the absence of clear results validating more weight being given to students directing discussion, the instructor seems more responsible to draw a balance in discussions, both "answering direct questions and providing clues or hints while facilitating discussion" [24]. One study also revealed instructors in online discussions may rely more heavily on social rather than cognitive codes. While students learn from different types of discursive interactions, they do favour instructors who balance comments across all types of interactions [24].

More information is needed: "a comprehensive framework with a set of criteria is essential for facilitating interactions....would make explicit to students the expectations of their engagement in discussions, and thereby shape that engagement" [24]. Research has begun to find ways to increase engagement of learners with "meaningful assessment, integrated, clear criteria" but there are a "number of confounding variables" including the difficulty in determining the best framework for examining collaborative dynamics and critical thinking [24]. There are no conclusive results which can determine "definitive qualities and characteristics associated with effective use of this form of instruction" [27].

\section{CONCLUSIONS AND IMPLICATIONS}

Best practices of instructors should be based on currently observed documented trends in both research and practice. As scholarship in online learning continues, it would be valuable to investigate some of the other ideologies which could inform not only basic understanding of the dynamics within an online course environment, but which can perhaps lend perspective as researchers and educators attempt to suggest more learner and course-specific guidelines around evolving best practices. 
This is an emerging field: the scope for qualitative, and quantitative study, both short term-and longitudinal is broad. The original search included four years of research compiled on one database. While sound, preliminary observations can be made in many areas concerning online teaching practices of the instructor, each area has room for additional empirical study. The complete study organizes what is known in areas that are important to the online instructor: technological design considerations, unique group and individual learner characteristic, and most importantly, the teaching, social and cognitive presence of the instructor. Further theoretical study, which is framed around a $\mathrm{COI}$ model but also effectively integrates other emerging considerations would continue to be beneficial for instructors and other levels of educators who seek to link good pedagogy with best practice in an online environment.

\section{REFERENCES}

[1] Garrison, Anderson \& Archer, 2001 cited in Shea, Peter; Bidjerano, Temi. (September 2012). Learning Presence as a Moderator in the Community of Inquiry Model. Computers \& Education, 59.2, pp. 316-326.

[2] Snyder, Martha M.; Dringus, Laurie P. (2014). An Exploration of Metacognition in Asynchronous Student-Led Discussions: A Qualitative Inquiry. Journal of Asynchronous Learning Networks, 18.2, pp. 1-2.

[3] Kang, Myunghee; Liew, BaoYng Teresa; Kim, Jiyoon; Park, Young. (July 2014). Learning Presence as a Predictor of Achievement and Satisfaction in Online Learning Environments. International Journal on E-Learning, 13.2, pp. 193-208.

[4] Barber, Wendy; King, Sherry; Buchanan, Sylvia. (2015). Problem Based Learning and Authentic Assessment in Digital Pedagogy: Embracing the Role of Collaborative Communities. Electronic Journal of e-Learning, 13:2, pp. 59-67.

[5] McDonald, Paige L.; Lyons, Laurie B.; Straker, Howard O.; Barnett, Jacqueline S.; Schlumpf, Karen S.; et al. (November 2014). Educational Mixology: A Pedagogical Approach to Promoting Adoption of Technology to Support New Learning Models in Health Science Disciplines. Online Learning. 18.4, p.18.

[6] Nye, Adele. (2015). Building an Online Academic Learning Community among Undergraduate Students. Distance Education, 36, 1, pp.115-128.

[7] Pittaway, Sharon M.; Moss, Timothy. (July 2014). Initially, We Were Just Names on a Computer Screen: Designing Engagement in Online Teacher Education. Australian Journal of Teacher Education, 39.7, p. 18.

[8] Johnson, Bruce A. (October 2014). Transformation of Online Teaching Practices through Implementation of Appreciative Inquiry. Online Learning, 18.3, p. 22.

[9] Kruger-Ross, Matthew J.; Waters, Richard D. (February 2013). Predicting Online Learning Success: Applying the Situational Theory of Publics to the Virtual Classroom. Computers \& E Education, 61, pp. 176-184.

[10] Dziuban, Charles; Moskal, Patsy; Thompson, Jessica; Kramer, Lauren; DeCantis, Genevieve; et al. (March 2015). Student Satisfaction with Online Learning: Is It a Psychological Contract? Online Learning, 19.2, 15. Education, 61, pp.176-184.

[11] Preisman, Kristi A. (October 2014). Teaching Presence in Online Education: From the Instructor's Point of View. Online Learning, 18.3, p. 16.

[12] Shea, Peter; Bidjerano, Temi. (September 2012). Learning Presence as a Moderator in the Community of Inquiry Model. Computers \& Education, 59.2.

[13] Redmond, Petrea; Devine, Jo; Basson, Marita. (2014). Exploring Discipline Differentiation in Online Discussion Participation. Australasia Journal of Educational Technology, 30.2, pp. 122-135.

[14] Fletcher, Gillian; Dowsett, Gary W. (2012). Actively Promoting Student Engagement within an Online Environment: Developing and Implementing a Signature Subject on "Contemporary Issues in Sex and Sexuality". Austin Lilian Journal of University Teaching and Learning Practice, 9.3 p.12. 
[15] Wise, Alyssa Friend; Speer, Jennifer; Marbouti, Farshid; Hsiao, Ying-Ting. (2013). Broadening the Notion of Participation in Online Discussions: Examining Patterns in Learners' Online Listening Behaviors. Instructional Science, 41.2, pp. 323-343.

[16] Ruckert, Elizabeth; McDonald, Paige L.; Birkmeier, Marissa; Walker, Bryan; Cotton, Linda; et al. (November 2014). Using Technology to Promote Active and Social Learning Experiences in Health Professions Education. Online Learning, 18. pp.4, 23.

[17] McDonald, Paige L.; Lyons, Laurie B.; Straker, Howard O.; Barnett, Jacqueline S.; Schlumpf, Karen S.; et al. (November 2014). Educational Mixology: A Pedagogical Approach to Promoting Adoption of Technology to Support New Learning Models in Health Science Disciplines. Online Learning. 18. pp. 4, 9, 18.

[18] Espasa, Anna; Guasch, Teresa; Alvarez, Ibis M. (June 2013). Analysis of Feedback Processes in Online Group Interaction: A Methodological Model. Digital Education Review. pp.59-73.

[19] Palmer, Stuart; Holt, Dale. (2014). Development of Student and Academic Staff Perceptions of the Elements of an Online Learning Environment over Time. Australasian Journal of Educational Technology, 30.4, pp. 375-389.

[20] Chen, C.Y.; Pedersen, S. (2012). .Learners' Internal Management of Cognitive Processing in Online Learning. Innovations in Education and Teaching International, 49.4, pp.363-373.

[21] Veletsianos, George; Navarrete, Cesar C. (January 2012). Online Social Networks as Formal Learning Environments: Learner Experiences and Activities. International Review of Research in Open and Distance Learning, 13.1, pp.144-166.

[22] Park, Ji Yong. (2015). Student Interactivity and Teacher Participation: An Application of Legitimate Peripheral Participation in Higher Education Online Learning Environments. Technology, Pedagogy and Education, 24.3, pp. 389-406.

[23] Clarke, Lane W.; Bartholomew, Audrey. (October 2014). Digging beneath the Surface: Analyzing the Complexity of Instructors' Participation in Asynchronous Discussion. Online Learning, 18.3, p.22.

[24] Nandi, Dip; Hamilton, Margaret; Harland, James (2012). Evaluating the Quality of Interaction in Asynchronous Discussion Forums in Fully Online Courses. Distance Education, 33.1, pp. 5-30.

[25] Tsai, Chia-Wen. (2013). How to Involve Students in an Online Course: A Redesigned Online Pedagogy of Collaborative Learning and Self-Regulated Learning. International Journal of Distance Education Technologies, 11.3, pp.47-57.

[26] Chaiprasurt, Chantorn; Esichaikul, Vatcharaporn. (July 2013). Enhancing Motivation in Online Courses with Mobile Communication Tool Support: A Comparative Study. International Review of Research in Open and Distance Learning, 14.3, pp.377-401.

[27] Putman, Michael S.; Ford, Karen; Tancock, Susan. (2012). Redefining Online Discussions: Using Participant Stances to Promote Collaboration and Cognitive Engagement. International Journal of Teaching and Learning in Higher Education, 24.2, pp. 151-167.

[28] Park, Ji Yong. (2014). Course Evaluation: Reconfigurations for Learning with Learning Management Systems. Higher Education Research and Development, 33.5, pp. 992-1006.

[29] Muuro, Maina Elizaphan; Wagacha, Waiganjo Peter; Oboko, Robert; Kihoro, John. (December 2014). Students' Perceived Challenges in an Online Collaborative Learning Environment: A Case of Higher Learning Institutions in Nairobi, Kenya. International Review of Research in Open and Distance Learning, 15.6, pp. 132-161.

[30] Morrison-Saunders, Angus; Hobson, Julia. (2013). Being Subject-Centred: A Philosophy of Teaching and Implications for Higher Education. Issues in Educational Research, 23.2, p. 212226.

[31] Lee, Eunbae; Pate, Joseph A.; Cozart, Deanna. (July 2015). Autonomy Support for Online Students. TechTrends: Linking Research and Practice to Improve Learning, 59.4, p. 54-61.

[32] Buchanan, Tom; Sainter, Phillip; Saunders, Gunter. (April 2013). Factors Affecting Faculty Use of Learning Technologies: Implications for Models of Technology Adoption. Journal of Computing in Higher Education, 25.1, p. 111. 
[33] Lawanto, Oenardi; Santoso, Harry B.; Lawanto, Kevin N.; Goodridge, Wade. (July 2014). Self-Regulated Learning Skills and Online Activities between Higher and Lower Performers on a Web-Intensive Undergraduate Engineering Course. Journal of Educators Online, 11.3, p.32.

[34] Clarke, Lane W.; Kinne, Lenore. (2012). More than Words: Investigating the Format of Asynchronous Discussions as Threaded Discussions or Blogs. Journal of Digital Learning in Teacher Education, 29.1, pp. 4-13. 